\title{
Uterine Contraction Intensity
}

National Cancer Institute

\section{Source}

National Cancer Institute. Uterine Contraction Intensity. NCI Thesaurus. Code C92906.

The duration of an uterine contraction expressed as $\mathrm{mmHg}$. 